\title{
STRUCTURE OF DIFFERENT INDICATORS FOR EVALUATING ISOMETRIC LEG EXTENSORS EXPLOSIVE FORCE IN TOP LEVEL ATHLETES
}

\author{
Jelena Ivanović ${ }^{1}$ and Milivoj Dopsaj ${ }^{2}$ \\ ${ }^{1}$ Serbian Institute of Sport and Sports Medicine, Belgrade, Serbia \\ ${ }^{2}$ Faculty of Sport and Physical Education, Univerzity of Belgrade, Serbia
}

\begin{abstract}
SUMMARY
The aim of this work was to establish factore structure of different indicators force-time curve for evaluating the leg extensors explosiveness regarding different sports and both genders. The research included 378 examinees divided into 8 groups based on gender and training process distinctiveness they have been subjected to. To evaluate contractile characteristics of leg extensors, standardized equipment was used and standardized "seating leg press" test. The isometric force-time characteristics of the leg extensors were evaluated using the 15 variables during unilateral (dominant and nondominant leg) and bilateral exertions measured at 100 and $50 \%$ of the maximal force and at 100, 180 and $250 \mathrm{~ms}$ from the beginning of the muscle contraction. The results obtained in this study show that the measured characteristics of the leg extensors explosive force obtained in the bi and unilateral exertions, in regard to the various sports groups, have different structures as a function separate sets of factors influenced by different mechanisms than on training in various sports disciplines.
\end{abstract}

Key Words: factor structure, different trained athletes, force-time curve..

\section{INTRODUCTION}

In metrology procedures in sport (testing procedures) among the already established standards on measuring the maximal values of F-t curve, recognized in values of maximal isometric force $\left(\mathrm{F}_{\max }\right)$, general indicator of explosiveness $\left(\mathrm{RFDF}_{\max }\right)$ and general index of sinergy ( $\left.\mathrm{I}_{\mathrm{ndx}} \mathrm{SNG}_{\text {BASIC }}\right)$, it is necessary to addopt the specific and special characteristics of F-t curve, i.e. special and specific indicators of explosiveness. It is the matter of fact that while performing maximal quick movements of the extremities it is impossible to achieve absolute values of maximal force at the level of full contractile potential of the engaged muscle. Top level athletes in the competitive conditions most commonly perform movements in the time interval of maximal $300 \mathrm{~ms}$ (Andersen \& Aagaard, 2006). Therefore, any mean of targeted and specific physical fitness should be based on increasing the certain characteristics of explosiveness $\left(\mathrm{RFD}_{\max }\right)$, with the tendency to increase the given characteristics precisely in specific time interval of movement per- formance, i.e. in the early phase of muscle contraction (Andersen, Andersen, Zebis, \& Aagaard, 2010; Hakkinen, Komi, \& Kauhanen, 1987; Ivanović, Dopsaj, Ćopić, \& Nešić, 2011; Mero, 1988).

Purposefulness of the results on the athletes fitness level and the level of the tested physical property development are directly dependable on applied test and its specificity and sensitivity of the measuring. The specificity of the test in regard to the sports branch, directly affects the evaluation of the fitness level, since the information obtained during specific testing is more valid (Müller, Benko, Raschner, \& Schwameder, 2000; Зациорски, 1982; Wilson \& Murphy, 1996). One of the aims of this research was to find and verify better, i.e. more valid measures in order to evaluate contractile characteristics of the leg extensors isometric force in different trained top level athletes. Detecting the structure of the space defined as contractile characteristics of the leg extensors isometric force could enable us to detect regularities that rule between the elements of the system in regard to different trained population which con- 
sequently should get to the generally precised training process menagement from the aspect of different sports disciplines and in the function of gender. Besides, since all three types of load during movement have been used in sports, it is well known that locomotion - running, jumping, rebound, change of directions, makes the system of bilateral and unilateral exertion, this paper will observe the three regime of muscle contraction.

The suggested approach of the data analisis, which were gathered using the measuring instrument for measuring leg extensors force in the seating position in the conditions of bilateral and unilateral isometric exertion, will enable us to detect the regularities, that can apply among the tested properties of the different trained athletes system - force contractile characteristics, the acknowledgement on improving the technological training process in diferent disciplines will be complemented.

The aim of this paper was to establish factoral structure of the observed characteristics, i.e. F- $t$ curve indicators for evaluation of the leg extensors explosiveness in regard to different trained sports.

\section{METHODS}

The research included 378 examinees divided into 8 groups based on gender (male $n=236$ and female

TABLE 1

Descriptive statistics for both genders regarding different groups of sports.

\begin{tabular}{|c|c|c|c|c|c|c|c|c|c|c|}
\hline & \multicolumn{5}{|c|}{ Male } & \multicolumn{5}{|c|}{ Female } \\
\hline & $\begin{array}{l}\mathrm{BM} \\
(\mathrm{kg}) \\
\end{array}$ & $\begin{array}{l}\mathrm{BH} \\
(\mathrm{cm}) \\
\end{array}$ & $\begin{array}{c}\text { BMI } \\
\left(\mathrm{kg} / \mathrm{m}^{2}\right) \\
\end{array}$ & $\begin{array}{c}\text { A } \\
\text { (yeras) } \\
\end{array}$ & $\begin{array}{c}\mathrm{TP} \\
\text { (years) }\end{array}$ & $\begin{array}{l}\mathrm{BM} \\
(\mathrm{kg}) \\
\end{array}$ & $\begin{array}{l}\mathrm{BH} \\
(\mathrm{cm}) \\
\end{array}$ & $\begin{array}{c}\text { BMI } \\
\left(\mathrm{kg} / \mathrm{m}^{2}\right)\end{array}$ & $\begin{array}{c}\text { A } \\
\text { (yeras) }\end{array}$ & $\begin{array}{c}\mathrm{TP} \\
\text { (years) }\end{array}$ \\
\hline \multicolumn{11}{|c|}{ Speed-strength sports (male $n=40$; female $n=34$ ) } \\
\hline$M$ & 80.61 & 182.10 & 24.23 & 21.48 & 10.95 & 66.44 & 169.29 & 23.16 & 21.65 & 11.06 \\
\hline$S D$ & 13.81 & 7.72 & 3.33 & 3.43 & 3.34 & 19.52 & 7.41 & 6.92 & 3.32 & 3.19 \\
\hline$c V \%$ & 17.13 & 4.24 & 13.73 & 15.99 & 30.46 & 29.37 & 4.38 & 29.86 & 15.34 & 28.85 \\
\hline Min & 59.00 & 169.00 & 18.01 & 18.00 & 8.00 & 50.00 & 154.00 & 17.41 & 18.00 & 8.00 \\
\hline Max & 130.00 & 203.00 & 37.18 & 31.00 & 20.00 & 163.20 & 184.00 & 60.38 & 29.00 & 22.00 \\
\hline \multicolumn{11}{|c|}{ Sports with complex exertion of all motoric properties (male $n=99$; female $n=43$ ) } \\
\hline$M$ & 83.35 & 183.97 & 24.57 & 22.24 & 11.87 & 67.49 & 175.45 & 21.89 & 21.16 & 11.27 \\
\hline$S D$ & 11.60 & 6.97 & 2.66 & 4.31 & 3.72 & 8.92 & 10.42 & 1.92 & 2.79 & 2.83 \\
\hline$c V \%$ & 13.92 & 3.79 & 10.84 & 19.37 & 31.38 & 13.22 & 5.94 & 8.87 & 13.16 & 25.11 \\
\hline Min & 51.00 & 162.00 & 18.87 & 17.00 & 8.00 & 53.00 & 158.00 & 18.59 & 17.00 & 7.00 \\
\hline $\operatorname{Max}$ & 115.00 & 201.00 & 33.60 & 35.00 & 27.00 & 87.40 & 196.00 & 26.99 & 27.00 & 18.00 \\
\hline \multicolumn{11}{|c|}{ Endurance sports (male $n=64$; female $n=33$ ) } \\
\hline$M$ & 82.36 & 186.67 & 23.57 & 23.88 & 11.27 & 60.91 & 171.70 & 20.57 & 22.45 & 8.97 \\
\hline$S D$ & 10.18 & 8.02 & 1.80 & 5.04 & 3.58 & 8.61 & 7.31 & 1.69 & 5.48 & 1.76 \\
\hline $\mathrm{cV} \%$ & 12.36 & 4.30 & 7.62 & 21.11 & 31.76 & 14.13 & 4.26 & 8.19 & 24.42 & 19.61 \\
\hline Min & 65.00 & 171.00 & 18.52 & 17.00 & 8.00 & 48.00 & 160.00 & 17.99 & 17.00 & 7.00 \\
\hline $\operatorname{Max}$ & 105.00 & 204.00 & 29.71 & 37.00 & 25.00 & 82.00 & 186.00 & 24.39 & 37.00 & 14.00 \\
\hline \multicolumn{11}{|c|}{ Control group (male $n=33$; female $n=32$} \\
\hline$M$ & 80.93 & 181.24 & 24.57 & 24.77 & & 60.36 & 167.63 & 21.47 & 23.16 & \\
\hline$S D$ & 10.91 & 5.59 & 2.51 & 5.09 & & 6.29 & 6.18 & 1.91 & 4.69 & \\
\hline $\mathrm{cV} \%$ & 13.48 & 3.08 & 10.20 & 20.55 & & 10.42 & 3.68 & 8.91 & 20.26 & \\
\hline Min & 56.00 & 171.00 & 19.15 & 18.00 & & 47.00 & 155.00 & 18.42 & 18.00 & \\
\hline Max & 109.00 & 197.00 & 30.51 & 34.00 & & 75.00 & 180.00 & 28.04 & 34.00 & \\
\hline
\end{tabular}

Legend: BM - Body mass; BH - Body hight; BMI - Bod mass index A - Ages; TP - Training period; $M$ - Mean; $S D$ - Standard deviation; $c V \%$ - Coefficient of variation; $M i n$ - Minimum; Max - Maximum; $\boldsymbol{n}$ - Number of respondents. 
$n=142$ ) and training process distinctiveness they have been subjected to: top level athletes from the speedstrength sports (different track, up to $400 \mathrm{~m}$ and field, jumps and throws, disciplines of athletics, weightlifters, gymnasts, skiers and sprint disciplines, up to 200 $\mathrm{m}$, in swimming; male $n=40$ and female $n=34$ ), top level athletes from the sports with complex exertion of all motoric properties (volleyball, handball, basketball, football, water polo and martial arts - judo, wrestling, boks, taekvondo, fencing; male $n=99$ and female $n=43$ ), top level athletes from the endurance sports (middle and long distance disciplines of athletics, rowers, swimming disciplins, under $400 \mathrm{~m}$, cyclists, triathletes; male $n=64$ and female $n=33$ ) and controls consisting of healthy untrained adults, both genders (male $n=33$ and female $n=32$ ).

\section{Variables}

Measurement range was defined by 15 variables regarding the contractile characteristics of leg extensors isometric force measured both unilateral (dominant $-\mathrm{RFD}_{\mathrm{DO}}$ and nondominant $-\mathrm{RFD}_{\mathrm{ND}}$ leg) and bilateral (RFD) regime of muscle contraction:

- Indicator of the basic (general) isometric leg extensors explosive force bilateral and unilateral (dominant and nondominant leg), was done by applying the following procedure (Ivanović, Dopsaj, \& Nešić, 2011; Zatsiorsky \& Kreamer, 2006):

$$
\begin{gathered}
\text { Bilateral }-\mathrm{RFD}_{\text {Fmax }}=\mathrm{F}_{\text {max }} / \mathrm{tF}_{\max } \\
\text { Dominant leg }-\mathrm{RFD}_{\text {FmaxDO }}=\mathrm{F}_{\text {maxDO }} / \mathrm{tF}_{\operatorname{maxDO}} \\
\text { Nondominant leg }-\mathrm{RFD}_{\text {FmaxND }}=\mathrm{F}_{\text {maxND }} / \mathrm{tF}_{\operatorname{maxND}}
\end{gathered}
$$

Where: $\mathrm{F}_{\max }, \mathrm{F}_{\max \mathrm{DO}}, \mathrm{F}_{\operatorname{maxND}}$ represents the maximal value of isometric leg extensors force achieved, bilateral and unilateral (dominant and nondominant leg), and $\mathrm{tF}_{\text {max }}, \mathrm{tF}_{\text {maxDO }}, \mathrm{tF}_{\text {maxND }}$ represents the time in s necessary to reach it bilateral and unilateral (dominant and nondominant leg), expressed in $\mathrm{N} \cdot \mathrm{s}^{-1}$.

- The indicator of specific isometric leg extensors explosive force or the $\mathrm{S}$ gradient of the leg extensors force, as a rate of force development measured at $50 \%$ of $\mathrm{F}_{\max }$, bilateral and unilateral (dominant and nondominant leg), was measured by applying the following procedure (Ibid):

$$
\text { Bilateral }-\mathrm{RFD}_{50 \%}=\mathrm{F}_{50 \%} / \mathrm{tF}_{50 \%}
$$

Dominant leg- $\mathrm{RFD}_{50 \% \mathrm{DO}}=\mathrm{F}_{50 \% \mathrm{DO}} / \mathrm{tF}_{50 \% \mathrm{DO}}$

$$
\text { Nondominant leg- } \mathrm{RFD}_{50 \% \mathrm{ND}}=\mathrm{F}_{50 \% \mathrm{ND}} / \mathrm{tF}_{50 \% \mathrm{ND}}
$$

Where: $\mathrm{RFD}_{50 \%}, \mathrm{RFD}_{0 \%}, \mathrm{RFD}_{50 \% \mathrm{ND}}$ represents the value of isometric force achieved at $50 \%$ of
$\mathrm{F}_{\max }$, bilateral and unilateral (dominant and nondominant leg), and $\mathrm{tF}_{50 \%}, \mathrm{tF}_{50 \% \mathrm{DO}}, \mathrm{tF}_{50 \% \mathrm{ND}}$ represents the time in s necessary to reach it bilateral and unilateral (dominant and nondominant leg), expressed in $\mathrm{N} \cdot \mathrm{s}^{-1}$.

- The indicator of special level of leg extensors explosive force development $\mathrm{RFD}_{250 \mathrm{~ms}}$, measured at time zone of SSC, i.e. at $250 \mathrm{~ms}$ of $\mathrm{tF}_{\text {max }}$, bilateral and unilateral (dominant and nondominant leg), was done by applying the following procedure (Ibid):

Bilateral $-\mathrm{RFD}_{250 \mathrm{~ms}}=\mathrm{F}_{250 \mathrm{~ms}} / \mathrm{tF}_{250 \mathrm{~ms}}$ Dominant leg $-\mathrm{RFD}_{250 \mathrm{~ms} \mathrm{DO}}=\mathrm{F}_{250 \mathrm{msDO}} / \mathrm{tF}_{250 \mathrm{msDO}}$ Nondominant leg $-\mathrm{RFD}_{250 \mathrm{msND}}=\mathrm{F}_{250 \mathrm{msND}} / \mathrm{tF}_{250 \mathrm{msND}}$ Where: $\mathrm{F}_{250 \mathrm{~ms}}, \mathrm{~F}_{250 \mathrm{msDO}}$ and $\mathrm{F}_{250 \mathrm{msND}}$ represents the value of isometric force achieved at $250 \mathrm{~ms}$ of $\mathrm{F}_{\max }$, bilateral and unilateral (dominant and nondominant leg), and $\mathrm{tF}_{250 \mathrm{~ms}}, \mathrm{tF}_{250 \mathrm{msDO}}, \mathrm{tF}_{250 \mathrm{msND}}$ represents the time in $\mathrm{s}$ necessary to reach it bilateral and unilateral (dominant and nondominant leg), expressed in $\mathrm{N} \cdot \mathrm{s}^{-1}$.

- The indicator of special level of explosive force development $\mathrm{RFD}_{180 \mathrm{~ms}}$ measured at $180 \mathrm{~ms}$ of tFmax, bilateral and unilateral (dominant and nondominant leg), was done by applying the following procedure (Ibid):

Bilateral $-\mathrm{RFD}_{180 \mathrm{~ms}}=\left(\mathrm{F}_{180 \mathrm{~ms}} / \mathrm{tF}_{180 \mathrm{~ms}}\right)$

Dominant leg $-\mathrm{RFD}_{180 \mathrm{msDO}}=\mathrm{F}_{180 \mathrm{msDO}} / \mathrm{tF}_{180 \mathrm{msDO}}$ Nondominant leg $-\mathrm{RFD}_{180 \mathrm{msND}}=\mathrm{F}_{180 \mathrm{msND}} / \mathrm{tF}_{180 \mathrm{msND}}$

Where: $\mathrm{F}_{180 \mathrm{~ms}}, \mathrm{~F}_{180 \mathrm{msDO}}$ and $\mathrm{F}_{180 \mathrm{msND}}$ represents the value of isometric force achieved at $180 \mathrm{~ms}$ of $F_{\text {max }}$,bilateral and unilateral (dominant and nondominant leg), and $\mathrm{tF}_{180 \mathrm{~ms}}, \mathrm{tF}_{180 \mathrm{~ms} \mathrm{DO}}$ and $\mathrm{tF}_{180 \mathrm{msND}}$ represents the time in $\mathrm{s}$ necessary to reach it bilateral and unilateral (dominant and nondominant leg), expressed in $\mathrm{N} \cdot \mathrm{s}^{-1}$.

- The indicator of special level of explosive force development $\mathrm{RFD}_{180 \mathrm{~ms}}$, measured at $100 \mathrm{~ms}$ of tFmax, bilateral and unilateral (dominant and nondominant leg), was done by applying the following procedure (Ibid):

$$
\text { Bilateral }-\mathrm{RFD}_{100 \mathrm{~ms}}=\mathrm{F}_{100 \mathrm{~ms}} / \mathrm{tF}_{100 \mathrm{~ms}}
$$

Dominant leg $-\mathrm{RFD}_{100 \mathrm{msDO}}=\mathrm{F}_{100 \mathrm{msDO}} / \mathrm{tF}_{100 \mathrm{msDO}}$

Nondominant leg $-\mathrm{RFD}_{10 \mathrm{msND}}=\mathrm{F}_{100 \mathrm{msND}} / \mathrm{tF}_{100 \mathrm{msND}}$

Where: $F_{100 \mathrm{~ms}}, F_{100 \mathrm{msDO}}$ and $\mathrm{F}_{100 \mathrm{msND}}$ represents the value of isometric force achieved at $100 \mathrm{~ms}$ of $F_{\text {max }}$ bilateral and unilateral (dominant and nondominant leg), and $\mathrm{tF}_{100 \mathrm{~ms}}, \mathrm{tF}_{100 \mathrm{msDO}}, \mathrm{tF}_{100 \mathrm{msND}}$ represents the time in s necessary to reach it bilateral and unilateral (dominant and nondominant leg), expressed in $\mathrm{N} \bullet \mathrm{s}^{-1}$. 


\section{Measuring procedure}

To evaluate contractile characteristics of isometric leg extensors force (unilateral and bilateral), standardized equipment was used, i.e. metal device for measuring leg extensors isometric force, a tensiometric probe and standardized "seating leg extension" test. All data was recorded and analyzed using a specially designed software system (M_S_NI, Nikola Tesla Institute, Serbia, Belgrade) for purpose of control and monitoring athletes training at the Serbian Institute for Sport and Sport Medicine in Belgrade (Dopsaj \& Ivanović, 2011) (Figure 1).

\section{FIGURE 1}

The measuring device for assesing maximal leg extensors isometric force with the hardware-software system (a), tensiometric device within foot platform (b), force reader conected with the PC (c).
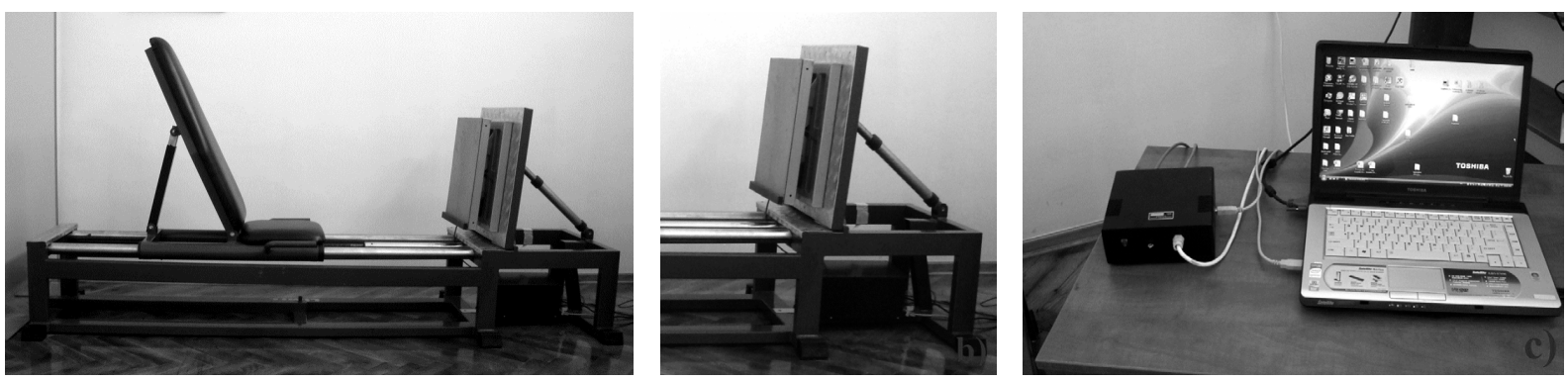

FIGURE 2

Exeminees position during measuring procedure.

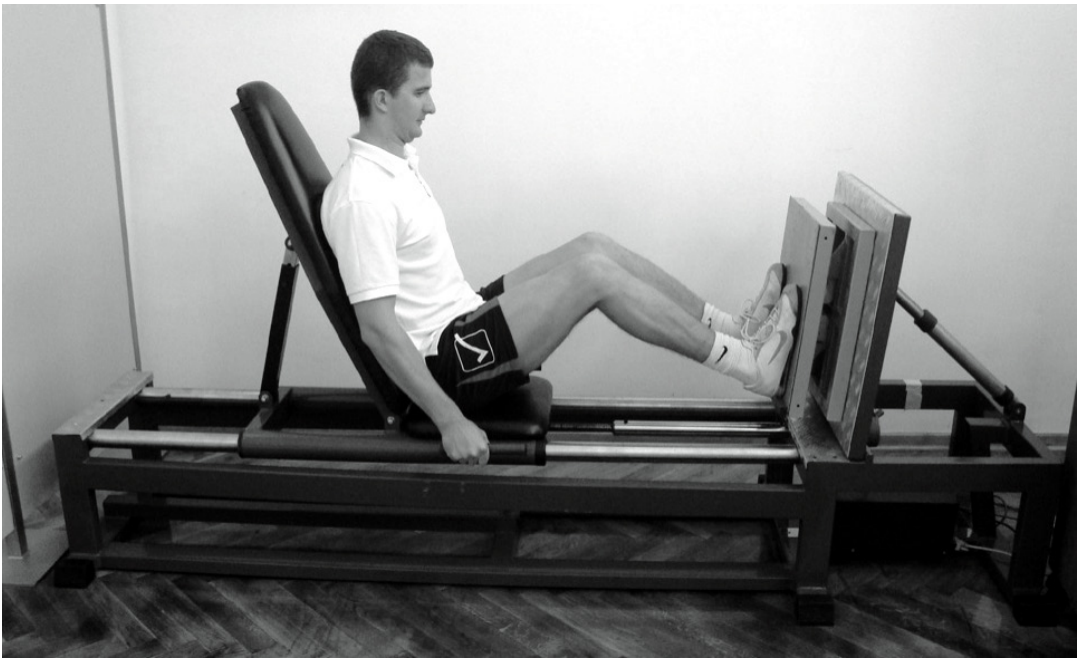

A foot-platform fixed to the frame by strain-gauge transducers and data was collected at $2000 \mathrm{~Hz}$ using interface box with an analog to digital card (National Instruments, Austin, TX, USA). During later off-line analysis the trials were selected and the force signal was filtered by a digital fourth order recursive low-pass filter, using a cutoff frequency of $50 \mathrm{~Hz}$. Thereafter, data was processed using a PC.

After individuals had warmed up for five minutes and received an introduction to the measuring procedure, each subject made two attempts in bilateral and four attempts in unilateral (dominant - nondominant - dominant - nondominant leg), with one minute of rest between trials. The subjects were instructed to exert their maximal force as quickly as possible in seating position (pushing with legs position). Hence, subjects were seated on a bench, so that their thigh and lower leg angle was at $120^{\circ}$, i.e. lower leg and foot angle $90^{\circ}$ (Figure 2). The subject performs the test trial based on a test leader instruction. The result was automatic, measured by the strain-gauge transducers and hardware-software system, recorded in a special database with the possibility of $F$ - $t$ curve inscription control (Figure 3). Best trial according to basic (general) isometric leg extensors explosive force was chosen for further statistical analysis.

\section{Statistical analysis}

For statistical analysis, in addition to the descriptive statistical model, for defining the structure, i.e. real 
qualitative relationships between variables, the multivariate analysis in the group of mutual dependence was used. The methods of interdependence is the method used confirmative factor analysis using the optimal rotation dependence (Oblimin).

Multivariate assessment of the adequacy of the raw data was carried out using measures $\mathrm{KMO}$
(Kaiser-Meyer-Olkin measure of sampling adequacy and Bartlett test of sphericity - Bartlett's Tests of sphericity), whose statistical significance was wxpressed in terms of a chi-square $\left(\chi^{2}\right)$ (Hair, Rolph, Ronald, \& William, 1998).

\section{FIGURE 3}

F-t curve.

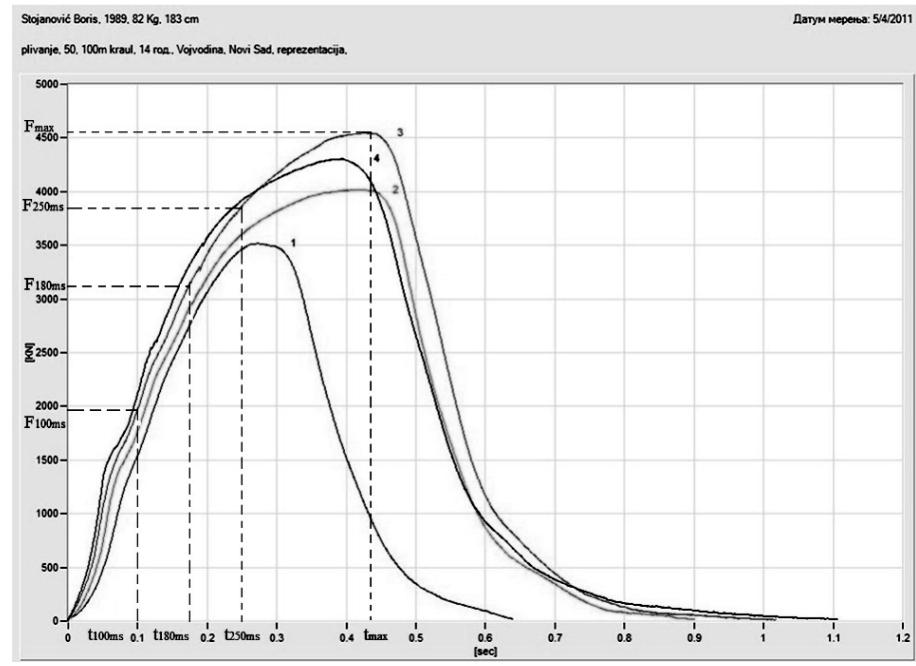

\section{RESULTS}

Table 2 shows the adequacy results in the given sample of the analized variables for subsample male examinees.

Table 3 shows abstracted factors with the structure indicators of the explained variance for the sample all observed variables.

Measure KMO showed high statistical significance of multivariate adequacy of the given variables for the examinees in group speed-strength sports at the level of .806 , i.e. $80.6 \%$, while $\chi^{2}$ test value was 1229.941. at the level of $p=.000$; for the examinees in group endurance sports at the level .737 , i.e. $73.7 \%$, while $\chi^{2}$ test value was 1760.349 , at the level of $p=.000$; for the examinees in the control group at the level .680 , i.e. $68.0 \%$, while $\chi^{2}$ test value was 913.941 . at the level of $p=.000$.

What this means is that measured data are valid to be used at the level of $68.0 \%$ (control group) to $80.6 \%$ (speed-strenght sports), which indicates that the rest of the variability in the amount of $32.0 \%$ (control group) to $19.4 \%$ (speed-strenght sports) has no valid adequacy and presents source of noise, respectivelly belongs to variability which can generally be assigned to the space that doesn't belong to the

TABLE 2

Values of The Kaiser-Meyer-Olkin Measure of Sampling Adequacy in male subsample.

\begin{tabular}{lrrrrr}
\hline Kaiser-Meyer-Olkin Measure & \multicolumn{1}{c}{1} & \multicolumn{2}{c}{2} & \multicolumn{1}{c}{3} & \multicolumn{1}{c}{4} \\
\cline { 2 - 6 } $\begin{array}{l}\text { of Sampling Adequacy } \\
\text { Bartlett's Test of Sphericity }\end{array}$ & .806 & .802 & .737 & .680 \\
\cline { 2 - 6 } & $\chi^{2}$ & 1229.941 & 2804.331 & 1760.349 & 913.941 \\
\cline { 2 - 6 } & $d f$ & 105 & 105 & 105 & 105 \\
\hline
\end{tabular}

Legend: 1 - Speed-strength sports; 2 - Sports with complex exertion of all motoric properties; 3 - Endurance sports; 4 - Conrol group; $\chi^{2}$ - Chi-Square test; $d f$ - Degrees of freedom; $p$ - Probability.. 
TABLE 3

Abstracted factors with the structure indicators of the explained variance.

\begin{tabular}{cccc}
\hline \multirow{2}{*}{ Component } & \multicolumn{3}{c}{ Extraction Sums of Squared Loadings } \\
\cline { 2 - 4 } & Total & \% of Variance & Cumulative \% \\
\hline \multicolumn{4}{c}{ Speed-strength sports } \\
\hline 1 & 10.413 & 69.418 & 69.418 \\
\hline 2 & 1.699 & 11.329 & 80.748 \\
\hline 3 & 1.073 & 7.152 & 87.899 \\
\hline \multicolumn{5}{c}{ Sports with complex exertion of all motoric properties } \\
\hline 1 & 9.193 & 61.285 & 61.285 \\
\hline 2 & 1.979 & 13.191 & 74.476 \\
\hline 3 & 1.256 & 8.376 & 82.852 \\
\hline 4 & 1.210 & 8.067 & 90.919 \\
\hline \multicolumn{5}{c}{ Endurance sports } \\
\hline 1 & 9.066 & 60.438 \\
\hline 2 & 2.148 & 14.317 & 60.438 \\
\hline 3 & 1.517 & 10.112 & 74.755 \\
\hline 4 & 1.022 & 6.815 & 84.866 \\
\hline \multicolumn{5}{c}{ Control group } \\
\hline 1 & 8.934 & 59.560 \\
\hline 2 & 2.718 & 18.120 \\
\hline 3 & 1.423 & 9.487 & 59.560 \\
\hline \multicolumn{4}{c}{} \\
\hline
\end{tabular}

given measurement (for example different methodic or accidental mistakes that arose during the measurement, the space of different examinee motivation when it comes to testing, the space of different examinee fitness level, etc...).

Table 4 shows the matrix of structure with the variables saturation in the function of the abstracted factors.

Factor analysis abstracted among the given variables three factors for the examinees in the group speedstrength sports and control group, and four factors for the examinees in the sports with the complex demonstration of motoric properties and in endurance sports (Table 2, 3), which cumulatively explained $87.899 \%$ of good varians for the examinees in the group speed-strenght sports; $91.682 \%$ for the examinees of endurance sports; $87.166 \%$ for the examinees in control group.

In speed-strength sports $80.6 \%$ of measured space which made the set of 15 variables was defined by 3 factors, with the high level of explained specificity at the level of $87.899 \%$ of the explained common variance.

In sports with the complex demonstration of motoric properties $80.2 \%$ of measured space which made the set of 15 variables was defined by 4 factorts, with the high level of explained specificity at the level of $90.919 \%$ of the explained common variance.

In endurance sports $73,7 \%$ of measured space which made the set of 15 variables was defined by 4 factorts, with the high level of explained specificity at the level of $91.682 \%$ of the explained common variance.

In control group $68.0 \%$ of measured space which made the set of 15 variables was defined by 3 factorts, with the high level of explained specificity at the level of $87.166 \%$ of the explained common variance.

Table 5 shows the results of adequacy regarding the given sample of the analized variables in the subsample female examinees.

Table 6 shows abstracted factors with the structure indicators of the explained variance for the sample - all of the observed variables.

Measure KMO shows high statistical significance of multivariate adequacy of the given variables for the examinees in group speed-strength sports at the level of .715 , i.e. $71.5 \%$, while $\chi^{2}$ test value is 831.927 . at the level of $p=.000$; for the examinees in group of sports with complex demontration of motoric properties at the level of .788 , i.e. $78.8 \%$, while $\chi^{2}$ testa value was 1300.777 , at the level of $p=.000$; for the examinees in group of endurance sports at the level 
TABLE 4

Structure Matrix in male subsample.

\begin{tabular}{|c|c|c|c|c|c|c|c|c|}
\hline \multirow{9}{*}{ 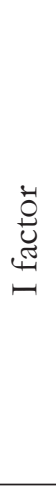 } & \multicolumn{2}{|c|}{ Speed-strength } & \multicolumn{2}{|c|}{ Complex } & \multicolumn{2}{|c|}{ Endurance } & \multicolumn{2}{|l|}{ Control } \\
\hline & $\mathrm{RFD}_{180 \mathrm{msND}}$ & .957 & $\mathrm{RFD}_{180 \mathrm{msND}}$ & .988 & $\mathrm{RFD}_{180 \mathrm{msND}}$ & .984 & $\mathrm{RFD}_{100 \mathrm{msND}}$ & .968 \\
\hline & $\mathrm{RFD}_{50 \% \mathrm{ND}}$ & .957 & $\mathrm{RFD}_{50 \% \mathrm{ND}}$ & .986 & $\mathrm{RFD}_{50 \% \mathrm{ND}}$ & .966 & $\mathrm{RFD}_{50 \% \mathrm{DO}}$ & .961 \\
\hline & $\mathrm{RFD}_{250 \mathrm{msND}}$ & .923 & $\mathrm{RFD}_{100 \mathrm{msND}}$ & .926 & $\mathrm{RFD}_{250 \mathrm{msND}}$ & .937 & $\mathrm{RFD}_{50 \% \mathrm{ND}}$ & .958 \\
\hline & $\mathrm{RFD}_{100 \mathrm{msND}}$ & .872 & $\mathrm{RFD}_{250 \mathrm{msND}}$ & .918 & $\mathrm{RFD}_{100 \mathrm{msND}}$ & .878 & $\mathrm{RFD}_{180 \mathrm{msDO}}$ & .946 \\
\hline & $\mathrm{RFD}_{180 \mathrm{~ms}}$ & .847 & & & & & $\mathrm{RFD}_{180 \mathrm{~ms} \mathrm{ND}}$ & .946 \\
\hline & $\mathrm{RFD}_{50 \%}$ & .847 & & & & & $\mathrm{RFD}_{100 \mathrm{msDO}}$ & .944 \\
\hline & $\mathrm{RFD}_{250}$ & .831 & & & & & $\mathrm{RFD}_{250 \mathrm{msDO}}$ & .942 \\
\hline & $\mathrm{RFD}_{100}$ & .782 & & & & & $\mathrm{RFD}_{250 \mathrm{msND}}$ & .885 \\
\hline \multirow{5}{*}{ 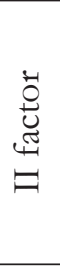 } & \multicolumn{2}{|c|}{ Speed-strength } & \multicolumn{2}{|c|}{ Complex } & \multicolumn{2}{|c|}{ Endurance } & \multicolumn{2}{|l|}{ Control } \\
\hline & $\mathrm{RFD}_{\mathrm{Fmax}}$ & .903 & $\mathrm{RFD}_{\text {FmaxDo }}$ & .897 & $\mathrm{RFD}_{180 \mathrm{~ms}}$ & .991 & $\mathrm{RFD}_{180 \mathrm{~ms}}$ & .991 \\
\hline & $\mathrm{RFD}_{\mathrm{FmaxND}}$ & .866 & $\mathrm{RFD}_{\text {FmaxND }}$ & .874 & $\mathrm{RFD}_{50 \%}$ & .982 & $\mathrm{RFD}_{50 \%}$ & .984 \\
\hline & $\mathrm{RFD}_{\mathrm{FmaxDO}}$ & .782 & $\mathrm{RFD}_{\mathrm{Fmax}}$ & .821 & $\mathrm{RFD}_{250 \mathrm{~ms}}$ & .938 & $\mathrm{RFD}_{250 \mathrm{~ms}}$ & .947 \\
\hline & & & & & $\mathrm{RFD}_{100 \mathrm{~ms}}$ & .924 & $\mathrm{RFD}_{100 \mathrm{~ms}}$ & .887 \\
\hline \multirow{5}{*}{ 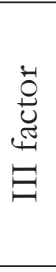 } & \multicolumn{2}{|c|}{ Speed-strength } & \multicolumn{2}{|c|}{ Complex } & \multicolumn{2}{|c|}{ Endurance } & \multicolumn{2}{|l|}{ Control } \\
\hline & $\mathrm{RFD}_{180 \mathrm{msDO}}$ & .989 & $\mathrm{RFD}_{180 \mathrm{msDO}}$ & .981 & $\mathrm{RFD}_{\mathrm{FmaxDO}}$ & .943 & $\mathrm{RFD}_{\mathrm{Fmax}}$ & .923 \\
\hline & $\mathrm{RFD}_{50 \% \mathrm{DO}}$ & .980 & $\mathrm{RFD}_{50 \% \mathrm{DO}}$ & .980 & $\mathrm{RFD}_{\mathrm{FmaxND}}$ & .926 & $\mathrm{RFD}_{\mathrm{FmaxND}}$ & .879 \\
\hline & $\mathrm{RFD}_{100 \mathrm{msDO}}$ & .956 & $\mathrm{RFD}_{100 \mathrm{msDO}}$ & .943 & $\mathrm{RFD}_{\mathrm{Fmax}}$ & .853 & $\mathrm{RFD}_{\text {FmaxDO }}$ & .636 \\
\hline & $\mathrm{RFD}_{250 \mathrm{msDO}}$ & .946 & $\mathrm{RFD}_{250 \mathrm{msDO}}$ & .888 & & & & \\
\hline \multirow{5}{*}{ 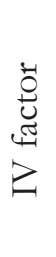 } & Speed-strer & gth & \multicolumn{2}{|c|}{ Complex } & \multicolumn{2}{|c|}{ Endurance } & \multicolumn{2}{|l|}{ Control } \\
\hline & & & $\mathrm{RFD}_{180 \mathrm{~ms}}$ & -.988 & $\mathrm{RFD}_{180 \mathrm{msDO}}$ & -.980 & & \\
\hline & & & $\mathrm{RFD}_{50 \%}$ & -.983 & $\mathrm{RFD}_{50 \% \mathrm{DO}}$ & -.973 & & \\
\hline & & & $\mathrm{RFD}_{100 \mathrm{~ms}}$ & -.946 & $\mathrm{RFD}_{100 \mathrm{msDO}}$ & -.962 & & \\
\hline & & & $\mathrm{RFD}_{250 \mathrm{~ms}}$ & -.936 & $\mathrm{RFD}_{250 \mathrm{t}}$ & -.888 & & \\
\hline
\end{tabular}

Legend: $\mathbf{R F D}_{\mathrm{DO}}$ - Dominant leg; $\mathbf{R F D}_{\mathrm{ND}}$ - Nondominant leg; Speed-strength - Speed-strength sports; Complex - Sports with complex exertion of all motoric properties; Endurance - Endurance sports; Control - Conrol group.

\section{TABLE 5}

Values of The Kaiser-Meyer-Olkin Measure of Sampling Adequacy in female subsample.

\begin{tabular}{lrrrrr}
\hline \multirow{2}{*}{$\begin{array}{l}\text { Kaiser-Meyer-Olkin Measure } \\
\text { of Sampling Adequacy }\end{array}$} & \multicolumn{1}{c}{1} & \multicolumn{2}{c}{2} & \multicolumn{1}{c}{3} & \multicolumn{1}{c}{4} \\
\cline { 2 - 6 } & & .715 & .788 & .809 & .718 \\
\hline \multirow{3}{*}{ Bartlett's Test of Sphericity } & $\chi^{2}$ & 831.927 & 1300.777 & 1042.572 & 827.770 \\
\cline { 2 - 6 } & $d f$ & 105 & 105 & 105 & 105 \\
\cline { 2 - 6 } & $p$ & $\mathbf{. 0 0 0}$ & $\mathbf{. 0 0 0}$ & $\mathbf{. 0 0 0}$ & $\mathbf{. 0 0 0}$ \\
\hline
\end{tabular}

Legend: 1 - Speed-strength sports 2 - Sports with complex exertion of all motoric properties; 3 - Endurance sports; 4 - Conrol group; $\chi^{2}$ - Chi-Square test; $d f$-Degrees of freedom; $p$ - Probability. 
.809 , i.e. $80.9 \%$, while $\chi^{2}$ test value was 1042.572 , at the level of $p=.000$; for the examinees in the control group at the level .718 , i.e. $71.8 \%$, while $\chi^{2}$ test value was 827.770. at the level of $p=.000$.

What this means is that measured data are valid to be used at the level of $71.5 \%$ (speed-strength sports) to $80.9 \%$ (endurance sports), which indicates that the rest of the variability in the amount of $28.5 \%$ (speedstraingth sports) to $19.1 \%$ (endurance sports) there is no valid adequacy and presents source of noise, respectivelly belongs to variability which can generally be assigned to the space that doesn't belong to the given measure (for example different methodic or accidental mistakes that arise during the measures, the space of different examinees motivation when it comes to testing, the space of different examinees fitness level, etc...).

Factor analysis abstracted four factors among the given variables for the examinees in the group speedstrength sports and control group, and three factors for the examinees in sports with the complex demonstration of motoric properties and endurance sports (Table 5, 6), which cumulatively explained 91.689\% of good varians for the examinees in group speedstrenght sports; $86.604 \%$ for the examinees in sports with complex demonstration of motoric properties;
$87.871 \%$ for the examinees of endurance sports; $91.235 \%$ for the examinees of control group.

Table 7 shows structure matrix with the saturation of the variables in the function of the abstracted factors.

In speed-strength sports $71.5 \%$ of measured space which made the set of 15 variables was defined by 4 factorts, with the high level of explained specificity at the level of $91.689 \%$ of the explained common variance.

In sports with the complex demonstration of motoric properties $78.8 \%$ of measured space which made the set of 15 variables was defined by 3 factorts, with the high level of explained specificity at the level of $86.604 \%$ of the explained common variance (Tabela 6,7).

In endurance sports $80.9 \%$ of measured space which made the set of 15 variables was defined by 3 factorts, with the high level of explained specificity at the level of $87.871 \%$ of the explained common variance.

In control group $71.8 \%$ of measured space which made the set of 15 variables was defined by 4 factorts, with the high level of explained specificity at the level of $91.235 \%$ of the explained common variance.

TABLE 6

Abstracted factors with the structure indicators of the explained variance.

\begin{tabular}{|c|c|c|c|}
\hline \multirow{2}{*}{ Component - } & \multicolumn{3}{|c|}{ Extraction Sums of Squared Loadings } \\
\hline & Total & $\%$ of Variance & Cumulative $\%$ \\
\hline \multicolumn{4}{|c|}{ Speed-strength sports } \\
\hline 1 & 8.141 & 54.276 & 54.276 \\
\hline 2 & 2.644 & 17.628 & 71.904 \\
\hline 3 & 1.908 & 12.723 & 84.627 \\
\hline 4 & 1.059 & 7.062 & 91.689 \\
\hline \multicolumn{4}{|c|}{ Sports with complex exertion of all motoric properties } \\
\hline 1 & 10.161 & 67.742 & 67.742 \\
\hline 2 & 1.655 & 11.034 & 78.776 \\
\hline 3 & 1.174 & 7.828 & 86.604 \\
\hline \multicolumn{4}{|c|}{ Endurance sports } \\
\hline 1 & 10.210 & 68.067 & 68.067 \\
\hline 2 & 1.728 & 11.518 & 79.584 \\
\hline 3 & 1.243 & 8.286 & 87.871 \\
\hline \multicolumn{4}{|c|}{ Control group } \\
\hline 1 & 8.046 & 53.640 & 53.640 \\
\hline 2 & 2.667 & 17.777 & 71.417 \\
\hline 3 & 1.550 & 10.336 & 81.753 \\
\hline 4 & 1.422 & 9.483 & 91.235 \\
\hline
\end{tabular}


TABLE 7

Structure Matrix in female subsample.

\begin{tabular}{|c|c|c|c|c|c|c|c|c|}
\hline \multirow{9}{*}{ 蔦 } & \multicolumn{2}{|c|}{ Speed-strength } & \multicolumn{2}{|c|}{ Complex } & \multicolumn{2}{|c|}{ Endurance } & \multicolumn{2}{|c|}{ Control } \\
\hline & $\mathrm{RFD}_{180 \mathrm{msNI}}$ & .993 & $\mathrm{RFD}_{180 \mathrm{msN}}$ & .959 & $\mathrm{RFD}_{180 \mathrm{~m}}$ & .959 & $\mathrm{RFD}_{180 \mathrm{mst}}$ & .961 \\
\hline & $\mathrm{RFD}_{50 \% \mathrm{ND}}$ & .966 & $\mathrm{RFD}_{50 \% \mathrm{ND}}$ & .948 & $\mathrm{RFD}_{250 \mathrm{msND}}$ & .932 & $\mathrm{RFD}_{50 \% \mathrm{ND}}$ & .947 \\
\hline & $\mathrm{RFD}_{100 \mathrm{msND}}$ & .915 & $\mathrm{RFD}_{250 \mathrm{msND}}$ & .940 & $\mathrm{RFD}_{180 \mathrm{msDO}}$ & .928 & $\mathrm{RFD}_{250 \mathrm{msND}}$ & .929 \\
\hline & $\mathrm{RFD}_{250 \mathrm{msND}}$ & .893 & $\mathrm{RFD}_{100 \mathrm{msND}}$ & .882 & $\mathrm{RFD}_{50 \% \mathrm{ND}}$ & .926 & $\mathrm{RFD}_{100 \mathrm{msND}}$ & .920 \\
\hline & & & $\mathrm{RFD}_{\mathrm{FmaxND}}$ & .816 & $\mathrm{RFD}_{50 \% \mathrm{DO}}$ & .916 & $\mathrm{RFD}_{250 \mathrm{msDO}}$ & .917 \\
\hline & & & $\mathrm{RFD}_{\mathrm{FmaxDO}}$ & .707 & $\mathrm{RFD}_{100 \mathrm{msND}}$ & .908 & $\mathrm{RFD}_{180 \mathrm{msDO}}$ & .888 \\
\hline & & & $\mathrm{RFD}_{\text {Fmax }}$ & .672 & $\mathrm{RFD}_{250 \mathrm{msDO}}$ & .899 & $\mathrm{RFD}_{50 \% \mathrm{DO}}$ & .869 \\
\hline & & & & & $\mathrm{RFD}_{100 \mathrm{msDO}}$ & .886 & $\mathrm{RFD}_{100 \mathrm{msDO}}$ & .783 \\
\hline \multirow{5}{*}{ 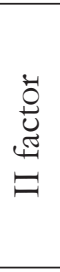 } & \multicolumn{2}{|c|}{ Speed-strength } & \multicolumn{2}{|c|}{ Complex } & \multicolumn{2}{|c|}{ Endurance } & \multicolumn{2}{|l|}{ Control } \\
\hline & $\mathrm{RFD}_{180 \mathrm{~ms}}$ & -.978 & $\mathrm{RFD}_{50 \%}$ & .969 & $\mathrm{RFD}_{180 \mathrm{~ms}}$ & -.990 & $\mathrm{RFD}_{180 \mathrm{~ms}}$ & .992 \\
\hline & $\mathrm{RFD}_{50 \%}$ & -.948 & $\mathrm{RFD}_{180 \mathrm{~ms}}$ & .954 & $\mathrm{RFD}_{50 \%}$ & -.989 & $\mathrm{RFD}_{50 \%}$ & .977 \\
\hline & $\mathrm{RFD}_{100 \mathrm{~ms}}$ & -.945 & $\mathrm{RFD}_{100 \mathrm{~ms}}$ & .936 & $\mathrm{RFD}_{250 \mathrm{~ms}}$ & -.971 & $\mathrm{RFD}_{250 \mathrm{~ms}}$ & .965 \\
\hline & $\mathrm{RFD}_{250 \mathrm{~ms}}$ & -.876 & $\mathrm{RFD}_{250 \mathrm{~ms}}$ & .869 & $\mathrm{RFD}_{100 \mathrm{~ms}}$ & -.069 & $\mathrm{RFD}_{100 \mathrm{~ms}}$ & .945 \\
\hline \multirow{5}{*}{ 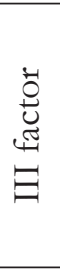 } & \multicolumn{2}{|c|}{ Speed-strength } & \multicolumn{2}{|c|}{ Complex } & \multicolumn{2}{|c|}{ Endurance } & \multicolumn{2}{|c|}{ Control } \\
\hline & $\mathrm{RFD}_{\mathrm{FmaxDO}}$ & .938 & $\mathrm{RFD}_{180 \mathrm{msDO}}$ & -.995 & $\mathrm{RFD}_{\mathrm{FmaxDO}}$ & .916 & $\mathrm{RFD}_{\mathrm{FmaxDO}}$ & .919 \\
\hline & $\mathrm{RFD}_{\mathrm{FmaxND}}$ & .866 & $\mathrm{RFD}_{50 \% \mathrm{DO}}$ & -.994 & $\mathrm{RFD}_{\mathrm{FmaxND}}$ & .807 & $\mathrm{RFD}_{\mathrm{FmaxND}}$ & .885 \\
\hline & $\mathrm{RFD}_{\mathrm{Fmax}}$ & .857 & $\mathrm{RFD}_{250 \mathrm{msDO}}$ & -.978 & $\mathrm{RFD}_{\text {Fmax }}$ & .774 & & \\
\hline & & & $\mathrm{RFD}_{100 \mathrm{msDO}}$ & -.965 & & & & \\
\hline \multirow{5}{*}{ 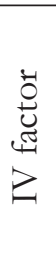 } & \multicolumn{2}{|c|}{ Speed-strength } & \multicolumn{2}{|c|}{ Complex } & \multicolumn{2}{|c|}{ Endurance } & \multicolumn{2}{|c|}{ Control } \\
\hline & $\mathrm{RFD}_{180 \mathrm{msDO}}$ & -.980 & & & & & $\mathrm{RFD}_{\mathrm{Fmax}_{\max }}$ & -.781 \\
\hline & $\mathrm{RFD}_{250 \mathrm{msDO}}$ & -.962 & & & & & & \\
\hline & $\mathrm{RFD}_{50 \% \mathrm{DO}}$ & -.894 & & & & & & \\
\hline & $\mathrm{RFD}_{100 \mathrm{msDO}}$ & -.777 & & & & & & \\
\hline
\end{tabular}

Legend: $\mathbf{R F D}_{\mathrm{DO}}$ - Dominant leg; $\mathbf{R F D}_{\mathrm{ND}}$ - Nondominant leg; Speed-strength - Speed-strength sports; Complex - Sports with complex exertion of all motoric properties;

Endurance - Endurance sports; Control - Conrol group.

\section{DISCUSSION}

It seems that the significance of the dominant leg has influenced the defining of structure characteristics of explosive force in regard with different sports groups (Table 4 and 7). The results obtained in this research show that measured characteristics of the leg extensors explosive force, obtained in bilateral and unilateral exertion regime in regard with different sports groups, have different structure in the function of abstracted factors under the impact/influence of different mechanisms in regard to training processes in different sports disciplines. Tables 4 and 7 and Figures 4 a 5 show abstracted factors in the function of different sports groups in respect to gender and from the aspect of absolute values of the explosive force development.

Based on the obtained results and analized variables of the First factor on the sample trained male exam- inees, it can be concluded that the differencies between altletes from these groups are most recognisable, i.e. the explosiveness of the non-dominant leg measured at the level of $180 \mathrm{~ms}$ is the most discriminating indicator. The reasons, especially when it comes to speed-strength group and group with complex demonstration of motoric properties, should be looked for in the simple fact that large number of athletes from the disciplines in which dominant leg plays an important role took part in this research (role of dominant leg in jump disciplines in field and track, different types of jumps with one leg in valleybal, basketball, handball, shoots, passings and dribbling ind football, specific postures and movements in fancing...).

In this case, non-dominant leg usually is not important for the successful conduction of certain motoric tasks, therefore contractile abilities of the leg 
FIGURE 4

Abstracted factors regarding male subsample.

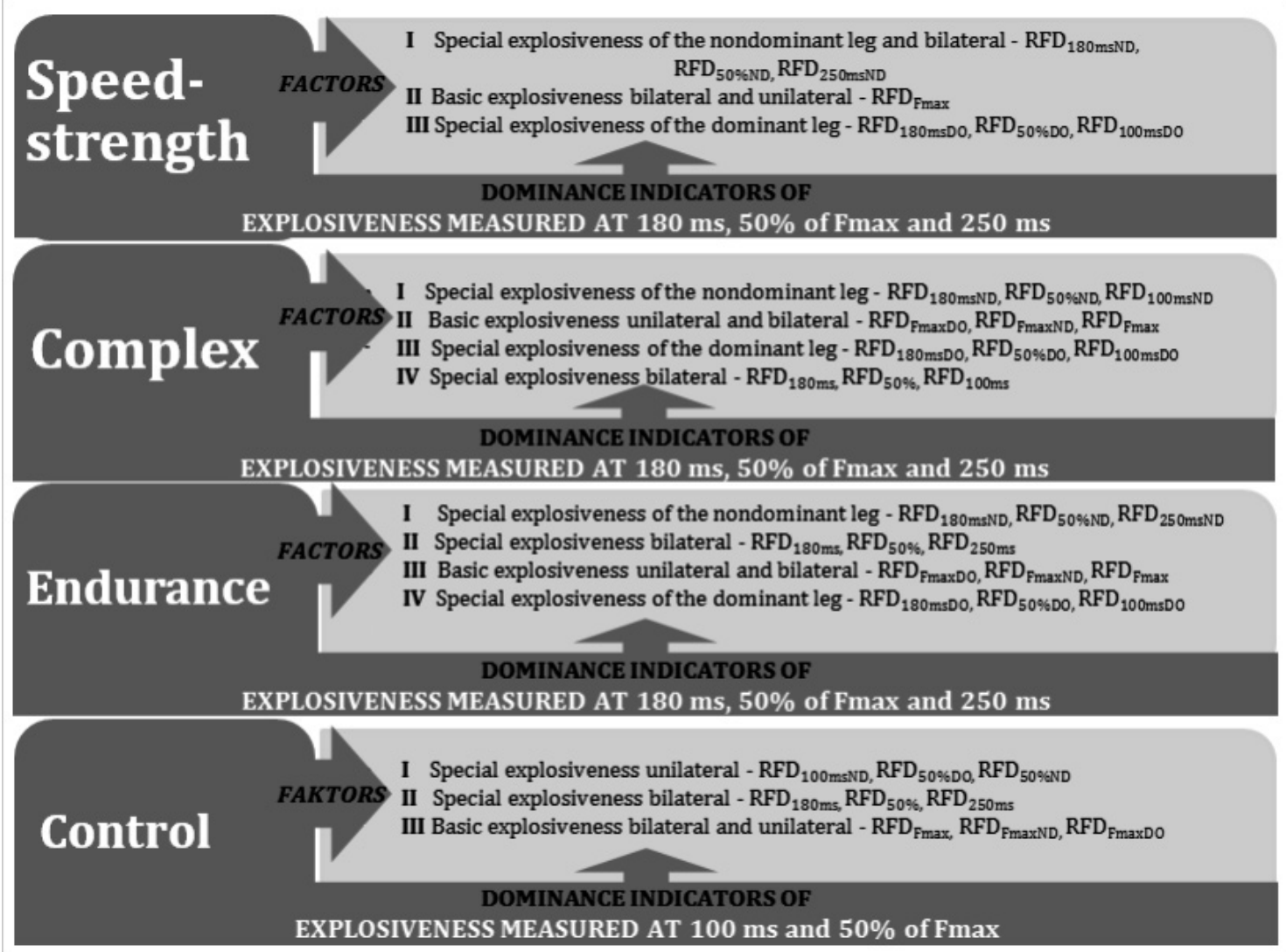

FIGURE 5

Abstracted factors regarding female subsample.

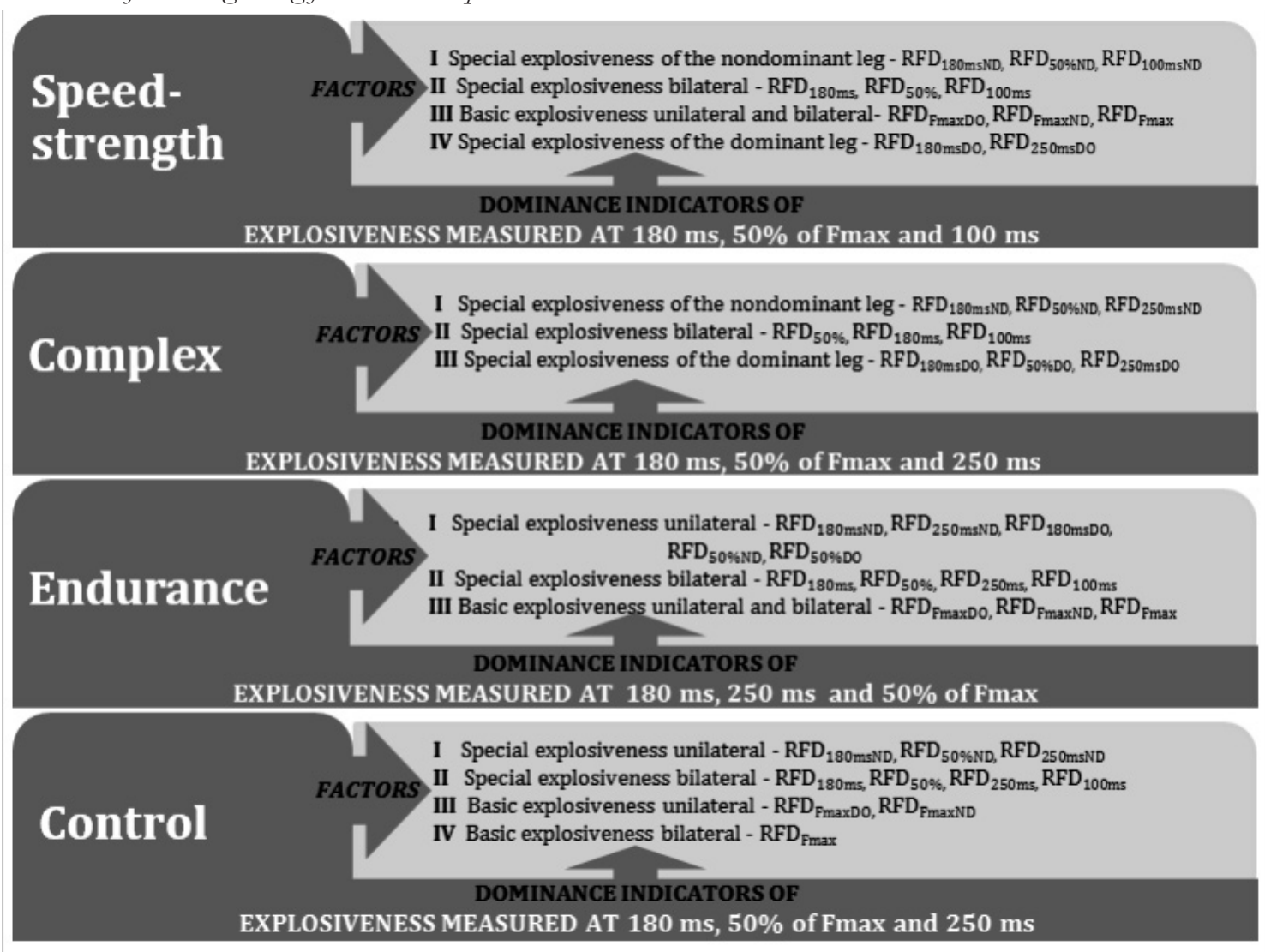


extensors aren't similary/adequate developed in all persons. Basic explosiveness is an indicator, i.e. analogy of general fitness level from the aspect of explosiveness. Given that the speed-strenght group was composed from the top level athletes, the fact that the second factor is saturated with the indicators of the general fitness level, which from the aspect of the priority in training process is in the background, isn't surprising. In fact, it is the base for the specific "functional fundament" in further tendency to increase productivity in sport. In case of top level athletes of speed-strenght sports, special fitness level and training process which should influence the high level of explosive force demonstration during the initial (early) phase of muscal contraction, that is extremlly important for successful movements, should dominate. The third factor is saturated with the indicators of specific, i.e. specialized fitness level from the aspect of explosiveness. Special explosiveness of the dominant leg measured at $180 \mathrm{~ms}$ is the least discriminating indicator for the athletes from this group. The reasons for the obtained results, as it has already been explained, should be looked for in the significant role of the dominant leg in the disciplines which made speed-strangth group.

Unlike speed-straingth athletes, the differencies between altletes from sports with complex demonstration of motoric abilities were the smallest, i.e. they were least discriminated by the special explosiveness measured in time interval of $180 \mathrm{~ms}$ and specific explosiveness bilateral. Time interval measured at $50 \%$ of maximal force presents the time for $\mathrm{S}$ gradient, i.e. starting/initial acceleration implementation/ ralization, while at the level of $180 \mathrm{~ms}$ it presents the most characteristic duration of contact with the ground during running in submaximal regime of exertion, abrupt changes in direction and vertical jumps (Čoh, 2010; Čoh \& Bošnjak, 2010; Gruber \& Gollhofer, 2004; Haff et al., 2005; Hakkinen, 1991; Ikemoto et al., 2007; Kraska et al., 2009; Zatsiorsky \& Kraemer, 2006). These time intervals are typical for sports with complex demonstration of motoric properties, so it is not strange that these indicators of explosiveness in the mentioned time intervals were abstracted as the last, IV factor.

Since group of endurance sports and control group were composed by top level athletes and physically active and health examinees who don't have dominant explosive movements, then it's not strange that the third and fourth factors, which have been saturated with the indicators of basic physical fitness level, the indicators that the examinees of the control group and group of endurance sports were least discrimi- nated by, and that are dominant from the aspect of priority when it comes to physical activities.

Based on the obtained results and analized variables of the First factor on the sample trained female examinees, it can be concluded that the differences between athletes from these groups were the largest, just like in male examinees, i.e. these examinees were most discriminated by the explosiveness of the nondominant leg measured at the level of $180 \mathrm{~ms}$. We can presume that the reasons of the obtained results are the same, taking into account that the same disciplines made both male and female groups of sports.

Unlike the male group of sports with complex demonstration of motoric abilities, the differences between female athletes from this group were the smallest, i.e. they were least discriminated by special explosiveness measured in time interval of $180 \mathrm{~ms}$ and specific explosiveness of dominant leg.

The obtained results indirectly confirm the results of our previous research where in regard to three groups of different trained female athletes, at the sample of absolute and relative parametres of leg extensors explosiveness, results showed differences in number, structure and composition of the abstracted factors under the influence of different mechanism in respect to training processes in different sports disciplines (Ivanović \& Dopsaj, 2011).

\section{CONCLUSIONS}

Based on the obtained results it could be concluded that different factor structure of the observed explosiveness indicators was determined in athletes, both male and female, from the different sports.

The results from this research show that measured characteristics of leg extensors explosive force, obtained in bilateral and unilateral exertion regime, and in respect to different sports groups, have different structure in the function of abstracted composition of factors under the influence of different mechanisms in regard to different training processes in different disciplines. From the aspect of determined differences in factor structure of the indicators for evaluatin the leg extensors explosiveness in regard with different sports, even more emphasise the influence of adoptation on muscle force characteristics demonstration, but on correlation between sports branch and the production of muscle force contractile characteristics.

Generally, it was determined, in both male and female examinees, that the most dominant isometric explosive force indicator of leg extensors was the indicator for the development level of force demostra- 
tion in non-dominant leg in time interval of $180 \mathrm{~ms}$ $\left(\mathrm{RFD}_{180 \mathrm{msND}}\right)$, therefore the main recommendation of this research would be to join it to the batery of already existing standard indicators $\left(\mathrm{F}_{\max }\right.$ and $\left.\mathrm{RFD}_{\mathrm{Fmax}}\right)$, as a most informative special indicators of explosive force.

\section{ACKNOWLEDGMENT}

The paper was realized as part of project III 47015 sponsored by Ministry of science and technological development in the Republic of Serbia.

\section{REFERENCES}

Andersen, L. L. \& Aagaard, P. (2006). Influence of maximal muscle strength and intrinsic muscle contractile properties on contractile rate of force development. European Journal of Applied Physiology, 96(1), 46-52. doi: 10.1007/s00421005-0070-z; PMid: 16249918

Andersen, L. L., Andersen, J. L., Zebis, M. K., \& Aagaard, P. (2010). Early and late rate of force development: differential adaptive responses to resistance training? Scandinavian Journal of Medicine \& Science in Sports, 20(1), 162-169. doi: 10.1111/j.1600-0838.2009.00933.x

Čoh, M. (2010). Biomechanical characteristics of take off action in high jump - a case study. Serbian Journal of Sports Sciences, 4(4), 127-135.

Čoh, M., \& Bošnjak, G. (2010). Neuro-mišićne karakteristike maksimalne sprinterske brzine [Neuromuscular characteristics of maximum sprint speed]. Sportlogia, 6(1), 28-35. doi: 10.5550/sgia.1001028

Dopsaj, M., \& Ivanović, J. (2011). The analysis of the reliability and factorial validity in the basic characteristics of isometric F-t curve of the leg extensors in well trained serbian males and females. Measurement Science Review, 11(5), 165172. doi: 10.2478/v10048-011-0027-9

Gruber, M., \& Gollhofer, A. (2004). Impact of sensorimotor training on the rate of force development and neural activation. European Journal of Applied Physiology, 92(1-2), 98-105. doi: 10.1007/s00421-004-1080-y; PMid: 15024669

Haff, G. G., Carlock, J. M., Hartman, M. J., Kilgore, J. L. , Kawamori, N., Jackson, J. R., ... Stone, M. H. (2005). Force-time characteristics of dynamic and isometric muscle actions of elite women Olympic weightlifters. Journal of Strength and Conditioning Research, 19(4), 741-748. doi: 10.1519/R-15134.1; doi: 10.1519/00124278200511000-00004
Hair, J. F., Rolph, E. A., Ronald, L. T., \& William, C. B. (1998). Multivariate Data Analysis. 5th Ed. New Jersey, NJ: Prentice - Hall, Inc.

Hakkinen, K. (1991). Force production characteristics of leg extensor, trunk flexor and extensor muscles in male and female basketball players. Journal of Sports Medicine and Physical Fitness, 31(3), 325-331.

Hakkinen, K., Komi, P. V., Alen, M., \& Kauhanen, H. (1987). EMG, muscle fibre and force production characteristics during a 1 year training period in elite weight-lifters. European Journal of Applied Physiology, 56(4), 419-427. doi: 10.1007/BF00417769

Ikemoto, Y., Demura, S., Yamaji, S., Minami, M., Nakada, N., \& Uchiyama, M. (2007). Force-time parameters during explosive isometric grip correlate with muscle power. Sport Sciences for Health, 2(2), 64-70. doi: 10.1007/s11332-0070041-3

Ivanović, J., Dopsaj, M., Ćopić, N., \& Nešić, G. (2011). Is there a relation between maximal and explosive leg extensors isometric force? Facta Universitatis Series: Physical Education and Sport, 9(3), 239-254.

Ivanović, J., Dopsaj, M., \& Nešić, G. (2011). Factor Structure differences of indicators for evaluating isometric leg extensors explosive force in female volleyball athletes and different trained female population. British Journal of Sports Medicine, 45(6), 542. doi: 10.1136/ bjsm.2011.084558.26

Kraska, J. M., Ramsey, M. V., Haff, G. G., Fethke, N., Sands, W. A., Stone, M. E., \& Stone, M. H. (2009). Relationship between strength characteristics and unweighted and weighted vertical jump height. International Journal of Sports Physiology and Performance, 4(4), 461-473.

Mero, A. (1988). Force-time characteristics and running velocity of male sprinters during acceleration phase of sprinting. Research Quarterly for Exercise \& Sport, 94(2), 94-98. doi: 10.1080/02701367.1988.10605484

Müller, E., Benko, U., Raschner, C. \& Schwamede. (2000). Specific fitness training and testing in competitive sports. Medicine and Science in Sports and Exercisec, 32(1), 216-220. doi: 10.1097/00005768-200001000-00032

Зациорски, В. (1982). Спортивная метрология [Sports metrology]. Москва: Физкультура и спорт.

Zatsiorsky, V. M., \& Kraemer, W. J. (2006). Science and practice of strength training. Champaign, IL: Human Kinetics. 
Wilson, G., \& Murphy, A. (1996). Strength diagnosis: The use of test data to determine specific strength training. Journal of Sports
Sciences, 14(2), 167-173. doi:

10.1080/02640419608727698; PMid: 8737324

Received: Decemeber 22, 2012

Revision received: Jun 5, 2013

Accepted: Jun 17, 2013

Correspondence to:

Jelena Ivanović, $\mathrm{PhD}$

Head of Analytics in Sports Section Serbian Institute of Sport and Sports Medicine,

Kneza Viseslava, 72

11030 Belgrade,

Serbia

Phone: 00381606410710

Fax: 00381113555288

E-mail: jelena.ivanovic@rzsport.gov.rs 